\title{
Strategic Partnerships to Enhance Data Structures and Algorithms Instruction at HBCUs
}

\author{
Kinnis Gosha \\ Morehouse College \\ Atlanta, GA \\ kinnis.gosha@morehouse.edu
}

\author{
Vinesh Kannan \\ Mimir Classroom \\ Dublin, $\mathrm{OH}$ \\ vinesh@mimirhq.com
}

\author{
Earl W. Huff Jr \\ Clemson University \\ Clemson, SC \\ earlh@clemson.edu
}

\author{
Lee Morgan \\ Mimir Classroom \\ Hekla, Iceland \\ lee@mimirhq.com
}

\begin{abstract}
The lack of diversity in technical roles among Silicon Valley tech titans is well-documented. Recruitment efforts have increased at minority serving institutions, however passing technical interviews remains a barrier for students. According to several sources, having a strong command of data structures and algorithms is pivotal to success in many technical interviews. To provide students more practice in these areas, College A partnered with Company B to co-develop a course in advanced data structures and algorithms. The course was taught to 29 students in Spring 2018 using Product $\mathrm{C}$, an online CS platform to assist the instructor with automated testing, plagiarism detection, and individual, targeted feedback. This experience report describes the co-development of the course, the execution of the course, and next steps for the partnership between College A and Company B.
\end{abstract}

\section{CCS CONCEPTS}

- Social and professional topics $\rightarrow$ Computing education;

\section{KEYWORDS}

Data Structures, Algorithms, HBCUs

\section{ACM Reference Format:}

Kinnis Gosha, Vinesh Kannan, Lee Morgan, and Earl W. Huff, Jr. 2019. Strategic Partnerships to Enhance Data Structures and Algorithms Instruction at HBCUs. In 2019 ACM Southeast Conference (ACMSE 2019), April 18-20, 2019, Kennesaw, GA, USA. ACM, New York, NY, USA, 4 pages. https: //doi.org/10.1145/3299815.3314457

\section{INTRODUCTION}

Previous work has detailed the lack of diversity at top technology firms such as Google, Amazon, Facebook and Apple [4]. Historically Black Colleges and Universities (HBCUs) provide companies a place

Permission to make digital or hard copies of all or part of this work for personal or classroom use is granted without fee provided that copies are not made or distributed for profit or commercial advantage and that copies bear this notice and the full citation on the first page. Copyrights for components of this work owned by others than ACM must be honored. Abstracting with credit is permitted. To copy otherwise, or republish, to post on servers or to redistribute to lists, requires prior specific permission and/or a fee. Request permissions from permissions@acm.org.

ACMSE 2019, April 18-20, 2019, Kennesaw, GA, USA

(C) 2019 Association for Computing Machinery.

ACM ISBN 978-1-4503-6251-1/19/04 . .\$15.00

https://doi.org/10.1145/3299815.3314457 to recruit for expanding their African American technical workforce. HBCUs play a significant role in preparing more people of color for the STEM careers of tomorrow. Even though the majority of black students (approximately 90\%) attend predominantly white institutions (PWIs), 21 of the top 50 institutions (42\%) for educating African-American graduates who go on to receive their doctorates in science and engineering, are HBCUs [7]. Even though HBCUs make up just 3 percent of colleges and universities, they produce 27 percent of African-American students with bachelor's degrees in STEM fields [7].

Recruitment efforts at HBCUs are in vain if potential candidates are not prepared to excel at technical interviews. Technical interviews have been the main criteria for employment as companies such as Google, IBM and Apple have removed the requirement for a college degree and disregard GPA in their evaluation of candidates [3]. Some schools have even created courses that prepare students to approach technical interviews [2]. Each company's approach to technical interviews is unique, however a strong command of data structures and algorithms is a typical requirement for most of these companies when it comes to hiring an entry-level software engineer.

\section{PARTNERSHIP}

College A partnered with Company B to create new assignments for an upper-level data structures course.

At the beginning of the relationship, the instructor of the course reached out to Company $\mathrm{B}$ requesting pre-populated questions about data structures and algorithms. Product $C$ is a curriculumagnostic tool for instructors to build and deliver their own courses, so it did not at that time include pre-built courses. After some negotiations, Company B agreed to build custom assignments for the instructor based on the set goals of the instructor.

Assignments were developed in three sets of deliverable, while the course was in session. The collaborators met virtually at the completion of each deliverable to discuss student feedback and ensure that the instructor was comfortable with the materials. 
Ultimately, more assignments were developed than could be used during the course. Assignments covering red-black trees, AVL trees, alternate hash collision-handling mechanisms, various graph representations, and various graph applications were not distributed to students and may be used in future classes.

\section{COURSE OVERVIEW}

The undergraduate course was listed as an alternative for the 400 level Organization of Programing Languages course. This is a required course for the CS degree. The course met twice a week on Tuesdays and Thursdays. Although the native language for the department is $\mathrm{C}++$, a decision was made to teach the class in Java to expand the array of languages learned by the students. In order to rapidly learn the language of Java, the instructor of the course assigned approximately 300 short coding exercises. The covered topics included Console IO, Primitive Types, Expressions, Assignment, Boolean Types and Branching statements. Students worked on these questions for the first three weeks of class. No lecture was given during this time. After this period, the instructor filled the course with a series of lectures, in-class assignments and take home coding assignments. Video lectures were pulled from YouTube to supplement the topics. The instructor played the videos in class while pausing multiple times to check if students understood the concepts taught in the video.

\subsection{Participants}

All 29 students who enrolled in the course have taken two semesters of Programming and one semester of Data Structures and Algorithms. Each of these classes are taught in $\mathrm{C}++$. One of the students was a senior CS major who cross registered from nearby HBCU. All the students were African American males. All but two students enrolled in the course completed the course. All students enrolled were classified as juniors or seniors.

\subsection{Pedagogical Aims}

Undergraduate data structures courses can vary widely, even within the US, so it is important to situate the pedagogical aims of this project. The instructor's rationale most closely relates to two themes from the categorization described by [5]:

- Improving students' programming skills

- Increasing knowledge of software libraries

An important goal of this upper-level course was to provide students practice programming in Java, so they could prepare for technical interviews in that language. The course introduced Java programming, reviewed data structures from the prerequisite course, then introduced new data structures. Since most students started as complete novices in Java, the course emphasized learning objectives similar to those of a CS2 course. The learning objectives resembled two objectives developed by [6]:

- Select appropriate abstract data types for use in a given application.

- Design and modify data structures capable of insertion, deletion, search, and related operations.

\subsection{Data Structures Assignments}

During the course, students individually completed eight major assignments. The assignments are explained here and given codes for brevity:

- DECODE: write a program to decode secret messages

- SQ1: apply stacks or queues to solve problems

- SQ2: apply stacks or queues to solve problems

- BST: implement a binary search tree

- HASH: apply hashsets and hashmaps to solve problems

- AVL: analyze an AVL tree

- TRIE: implement a trie

- SORT: implement and analyze sorting algorithms

DECODE, SQ1, SQ2, and BST were used as review assignments. DECODE contains no data structures-specific content but was the first assignment students completed in Java. SQ1 and SQ2 were originally designed as a single review assignment covering stacks and queues. The data structures "implementation" assignments, BST, TRIE, and SORT required student solutions to match a given interface of methods in order to receive credit. BST, HASH, and TRIE encouraged, but did not require, students to write their own test cases to evaluate their solution. SQ1, SQ2, HASH, and AVL also contained free response questions that either asked students to record observations from reading the relevant Java documentation or evaluate fictional co-workers' claims about the data structure in focus. AVL and TRIE included multiple choice questions meant to capture possible misconceptions about the data structure in focus. SORT included a task to produce a graph of the observed runtime complexity of sorting algorithms implemented by the student.

\subsection{Delivery and Assessment}

The core coursework was delivered on Product C. Student programs were assessed with automated test cases. Non-programming tasks were manually scored by the instructor. Students could make unlimited attempts on all assignments until the due date. Some programming tasks hid test case details and encouraged students to write their own test cases.

\subsection{Instructor Guides}

Anecdotally, it is uncommon for upper-level instructors at this college to keep detailed lesson plans. However, during the development of these course materials, many pieces of data structures content knowledge and pedagogical content knowledge emerged that would be difficult for an instructor to remember on their own. Company B developed Instructor guides offered a format to organize this knowledge in an actionable way, including sections describing:

- Assignment learning objectives

- Assessment recommendations

- Mappings between automated test cases and edge cases

- Possible student questions and instructor responses

- Possible student misconceptions

- Links to additional reading on the topic

These guides make the instructor aware of instructional design decisions made during course development, especially those that 
might help answer student questions, differentiate instruction based on learner needs, or settle grading disputes

\section{RESULTS}

Figure 1 shows the distribution of student grades for each assignment. Grades were scaled such that the maximum possible score for each assignment is 1 . Grades include penalties for late submissions. Students who did not submit received a grade of 0 . Figure 2

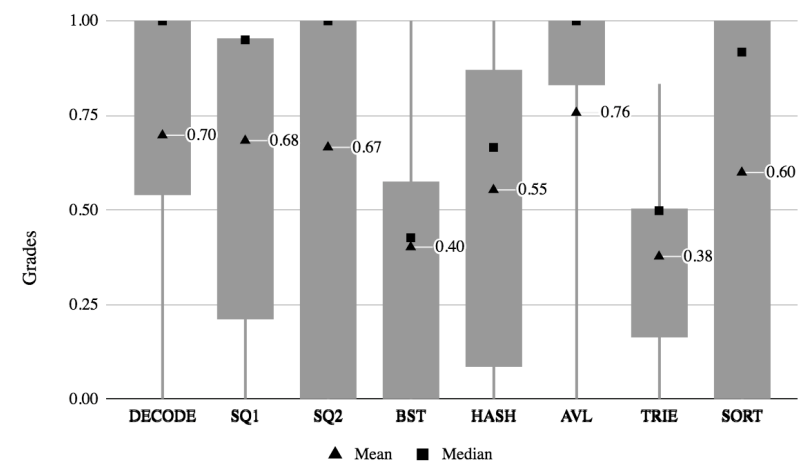

Figure 1: Box Plots Representing Distribution of Student Grades for the Eight Major Assignments. Mean Grades for the Entire Class are Labeled

shows the distribution of student attempts relative to the deadline. 20 students $(69 \%)$ submitted every assignment. Figure 3 and Figure

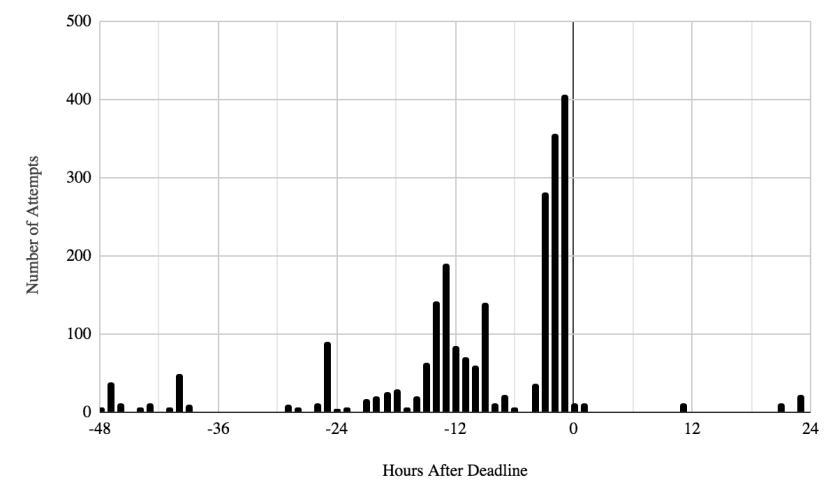

Figure 2: Distribution of Attempts up to Two Days Before the Deadline or up to One Day Afterward. All Eight Assignments are Combined. Negative Values on the Horizontal Axis Indicate Hours Before the Deadline, Zero Represents the Deadline

4 show the grade distributions for each assignment if students who did not submit the assignment are excluded. With the exception of DECODE and TRIE, excluding non-submitting students increases the class average for each assignment by more than a full letter grade ( 0.1 points). After excluding non-submitting students, BST and TRIE have the lowest scores across the class. For BST, $29.6 \%$ of

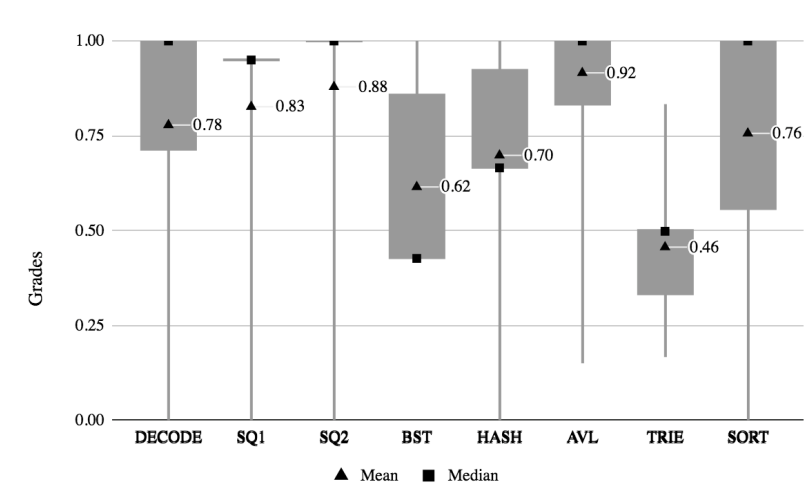

Figure 3: Box Plots Representing Distribution of Student Grades for the Eight Major Assignments, Excluding Students Who Did Not Submit. Mean Grades for this Subset are Labeled

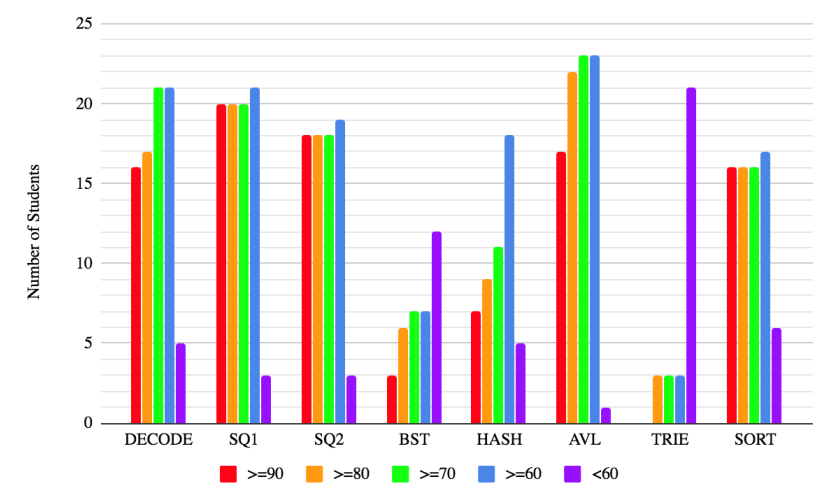

Figure 4: Distribution of Student Grades for the Eight Major Assignments, Excluding Students Who Did Not Submit. Score Groupings Correspond to Standard Letter Grades for the Course

students who submitted the assignment made a final submission that did not compile. For TRIE, $62.5 \%$ of students made a final submission that did not compile.

Table 1 shows the most difficult test cases from BST and TRIE, where less than $50 \%$ of students who submitted passed the test case. All of these test cases were found to be correct upon inspection by the designer. A modified version of item effect was used to identify test cases that were difficult for even for students who did well in the course. Item effect measures how well an item separates students who know the material from those who do not. The item effect calculation from [1] is not applicable here because these test cases assess the same code and are therefore not independent items. Instead, a modified item effect measure was computed with a pointbiserial correlation between the student's dichotomous test case result and the student's continuous overall grade across the eight assignments. An item effect score can be considered "good" if it is 
above 0.3 , otherwise "fair" if it is above 0.1 , and otherwise "poor" if it is below 0.1 [1]. BST TC3 tested whether or not a value could be

Table 1: Analysis of Difficult Test Cases from BST and TRIE. For Each Test Case: the Percentage of Students Who Passed the Test, the Average Course Grade of Students Who Passed the Test, the Average Course Grade of Students Who Failed the Test, and the Effect Rating

\begin{tabular}{|c|c|c|c|c|c|c|}
\hline A & TC & $\begin{array}{l}\text { Pass } \\
\text { Rate }\end{array}$ & $\begin{array}{l}\text { Avg. } \\
\text { Grade } \\
\text { (Pass) }\end{array}$ & $\begin{array}{l}\text { Avg. } \\
\text { Grade } \\
\text { (Fail) }\end{array}$ & $\begin{array}{l}\text { Item } \\
\text { Effect }\end{array}$ & $\begin{array}{l}\text { Item } \\
\text { Rating }\end{array}$ \\
\hline BST & TC1 & $26.3 \%$ & $80.6 \%$ & $76.3 \%$ & 0.136 & Fair \\
\hline BST & TC2 & $47.4 \%$ & $83.2 \%$ & $72.2 \%$ & 0.399 & Good \\
\hline BST & TC3 & $15.8 \%$ & $76.2 \%$ & $77.7 \%$ & -0.039 & Poor \\
\hline BST & TC4 & $21.1 \%$ & $90.3 \%$ & $74.0 \%$ & 0.483 & Good \\
\hline TRIE & TC1 & $12.5 \%$ & $80.1 \%$ & $70.1 \%$ & 0.1717 & Fair \\
\hline TRIE & TC2 & $0.0 \%$ & $\mathrm{~N} / \mathrm{A}$ & $71.3 \%$ & 0.000 & Poor \\
\hline TRIE & TC3 & $12.5 \%$ & $80.1 \%$ & $70.1 \%$ & 0.171 & Fair \\
\hline
\end{tabular}

retrieved from the tree immediately after deletion. Several students who failed this test case threw null pointer exceptions. TRIE TC2 tested whether or not students could retrieve strings regardless of their case. No student passed this test case. This can be considered an underspecified requirement because the problem description did not explicitly state that retrieval should be case insensitive nor did it provide examples for such inputs.

\section{DISCUSSION}

The following experience can be reviewed from two perspectives the analysis of the infused course and the analysis of the partnership between the corporate partner and the instructor. The partnership addressed a need from instructor by developing custom assignments, instructional guides and test cases in the area of advanced data structures and algorithms. Similar tools on the market had many of the same features, however they lacked pre populated assignments in the area of need. The instructor has a teaching load of nine credit hours per semester with requirements to do research, service, advise students and engage with multiple companies/graduate programs that come to the department to recruit students. The instructor was able to give more assignments without having to allocate the time to (a) develop the assignments and test cases, (b) grade the coding components of the assignments, (c) give feedback on coding assignments, (d) troubleshoot technical issues with the platform, (e) training students how to use the tool (f) check for plagiarism or (g) manually mining the course performance data to discover areas of opportunity and growth. By saving so much time for the instructor, he was then more motivated to continue to teach this course (which he felt more beneficial for the students) in future semesters instead of other courses the instructor is more comfortable teaching.

In terms of the course itself, their were many takeaways about how the course could be instructed better from analyzing the data from the platform. Two of the assignments (BST TRIE) had scores lower than the rest of the assignments. After discussions by the instructor and the company, there was no consensus why students performed lower on those two assignments. Thoughts included (a) the instructor taught those concepts less effectively than the others, (b) the assignments for those concepts were more rigorous, (c) the goals of those assignments were not as clear as the others or (d) those assignments required a higher level of competency in the programming language of Java. It was also unclear to the instructor and the company why students left open-ended questions blank. The hypothesis was that students ran out of time working on the coding components of the assignments.

\section{FUTURE WORK}

Both the instructor and the company enjoyed collaborating with each other and wish to continue collaborating in the future. There are several things that they agreed to do differently the next time this course is taught. First, Java concepts not learned at the beginning of the course will be taught throughout the course if it is needed in order to complete the upcoming assignment. Second, additional questions will be added to every assignment to assess if the students understand the abstract data types in addition to being able to implement the code. Third, students will be given a short survey to complete after every assignment to get their feedback about why they performed the way they did on that assignment. Included on the survey will be a question to address why they left an open-ended question blank (if that was indeed the case). Another question will ask if the IDE had any impact on if the assignment was completed or not. Lastly, students will be given an additional survey before graduating to see how the course has impact them in their pursuit to land full time technical employment.

\section{ACKNOWLEDGMENTS}

This work is supported by NSF Award Number 1547793 in the division of Division Of Human Resource Development.

\section{REFERENCES}

[1] [n. d.]. Understanding Item Analyses. http://www.washington.edu/assessment/ scanning-scoring/scoring/reports/item-analysis/

[2] 2017. CS9: Problem-Solving for the CS Technical Interview. http://web.stanford. $\mathrm{edu} / \mathrm{class} / \mathrm{cs} 9 /$

[3] C. Connley. 2018. Google, Apple and 12 other Companies that no Longer Require Employees to have a College Degree. https://www.cnbc.com/2018/08/16/ 15-companies- that-no-longer-require-employees-to-have-a-college-degree. html

[4] P. Hall Jr and K. Gosha. 2018. The Effects of Anxiety and Preparation on Performance in Technical Interviews for HBCU Computer Science Majors. In Proceedings of the 2018 ACM SIGMIS Conference on Computers and People Research - SIGMIS-CPR'18. ACM Press, New York, New York, USA, 64-69. https: //doi.org/10.1145/3209626.3209707

[5] R. Lister, I. Box, B. Morrison, J. Tenenberg, and D. S. Westbrook. 2004. The Dimensions of Variation in the Teaching of Data Structures. In Proceedings of the 9 th annual SIGCSE conference on Innovation and technology in computer science education - ITiCSE '04, Vol. 36. ACM Press, New York, New York, USA, 92. https: //doi.org/10.1145/1007996.1008023

[6] L. Porter, D. Zingaro, C. Lee, C. Taylor, K. C. Webb, and M. Clancy. 2018. Developing Course-Level Learning Goals for Basic Data Structures in CS2. In Proceedings of the 49th ACM Technical Symposium on Computer Science Education - SIGCSE '18. ACM Press, New York, New York, USA, 858-863. https://doi.org/10.1145/3159450. 3159457

[7] C. B. W. Prince and R. L. Ford. 2016. Setting a New Agenda for Student Engagement and Retention in Historically Black Colleges and Universities. https://books.google.com/books?hl=en\&lr=\&id=dlSiDAAAQBAJ\&oi=fnd\&pg= PR1\&dq=Setting+a+New+Agenda+for+Student+Engagement+and+Retention+ in+Historically+Black+Colleges + and+Universities\&ots=bOsQCgU0gM\&sig $=$ LTiYiolV_U6ALUgKwzrJ3-Uj-gw 